\title{
The Impact of Teachers' Experience and Qualification on Efficacy, Knowledge and Implementation of Differentiated Instruction
}

\author{
Visal Moosa \\ Corresponding Author, University Brunei Darussalam, Brunei Darussalam, \\ visal.moosa@gmail.com
}

Mariyam Shareefa

University Brunei Darussalam,Brunei Darussalam,maree2098@gmail.com

The purpose of this study is to investigate the differences in teachers' sense of efficacy, their knowledge, and implementation of DI based on their experience and qualification. The study also aims to investigate the moderating effect of teachers' experience and qualification. The study employs a tool composed of validated items and constructs from previous studies to collect data from a sample of 101 elementary teachers in a single atoll of Maldives. Parametric statistic of independent sample $t$-test and one-way ANOVA were used to investigate differences among groups of respondents while multiple regression using split sample was carried out to examine the moderation effect. Results indicate that there is a statistically significant difference in teachers' sense of efficacy across the three experience-groups, $F(2,93)=3.56, p=.032$. However, there is no significant difference in teachers' knowledge and implementation of DI based either on their experience or qualification. The results also indicate that neither teachers' experience nor their qualification was a significant moderator of the DI implementation model. It is recommended teachers be equipped with sufficient knowledge of DI by incorporating relevant content in teacher training programs.

Keywords: differentiated instruction, efficacy, knowledge, qualification, experience

\section{INTRODUCTION}

If there is a single instructional strategy that has the potential to address the challenges of meeting diverse needs of students in today's inclusive educational settings, Differentiated Instruction (DI) is, perhaps, the one (Logan, 2011). Despite the potential benefits of the strategies of DI in improving student learning, embracing change and adopting such an innovation has proven to be challenging for many teachers. There have been reports that implementation of DI strategies in many classrooms are infrequent,

Citation: Moosa, V., \& Shareefa, M. (2019). The Impact of Teachers' Experience and Qualification on Efficacy, Knowledge and Implementation of Differentiated Instruction. International Journal of Instruction, 12(2), 587-604. https://doi.org/10.29333/iji.2019.12237a 
inconsistent, and incorrect (Morrison-Thomas, 2016). As such, there is a need to find out what factors may affect teachers' implementation of DI strategies. This study investigates the influence of certain demographic variables, namely teaching experience and qualification, on teacher efficacy, knowledge and implementation of DI strategies.

There exist a plethora of research carried out on a wide range of topics related to DI (see, for example, Dixon, Yssel, Mcconnell, \& Hardin, 2014; Reis, Mccoach, Little, Muller, \& Kaniskan, 2011; Ruys, Defruyt, Rots, \& Aelterman, 2013; Seiler, 2014; Tomlinson et al., 2003; Tulbure, 2011). As has already been mentioned, the complexity of the concept and the difficulties in adopting DI strategies result in less use of them despite their plausible benefits in catering the diverse needs of leaners (Tomlinson, 1999). As such, researchers have been more attracted to studies pertaining to the investigation of teachers' implementation of DI strategies (see Baxter, 2013; McMillan, 2011; MorrisonThomas, 2016; Nedellec, 2015; Ricketts, 2014; Usher, 2013; Wu \& Chang, 2015).

In this regard, researchers have identified a number of variables that might influence teachers' implementation of DI strategies including their perception of DI (see Davis, 2013; Dixon, Yssel, McConnell, \& Hardin, 2014; Robinson, 2017; Santangelo \& Tomlinson, 2012; Xu, 2012), their knowledge of DI (Baxter, 2013; Brentnall, 2016; Chien, 2015; McMillan, 2011; Nedellec, 2015), their sense of efficacy (Casey, 2011; Dixon, Yssel, McConnell, and Hardin, 2014; De Neve, Devos, \& Tuytens, 2015; Holzberger, Philipp, \& Kunter, 2013), and challenges to implementation of DI (Joseph, Thomas, Simonette, \& Ramsook, 2013; Lange, 2009; Logan, 2011; Robinson, 2017; Siam \& Al-Natour, 2016).

Likewise, researchers have also recognized certain demographic factors that might affect proper DI implementation which includes, among others, number of years of teaching experience (Dixon et al., 2014; Garrett, 2017; Suprayogi, Valcke, \& Godwin, 2017), and educational or teaching qualification (Casey, 2011; McMillan, 2011; Suprayogi et al., 2017).

\section{CONCEPTUAL FRAMEWORK}

In the present study, DI model of Tomlinson (2014) was employed as the conceptual framework for measuring knowledge and implementation of DI. According to the model, teachers can differentiate a lesson based on content, process, product, and environment as stated in Figure 1 (Tomlinson, 1999; Tomlinson, 1999, 2000, 2001, 2008; Tomlinson \& Imbeau, 2014). In addition to Tomlinson's (1999) model, hypotheses of the present study are largely influenced by the extensive review of literature. The consulted literature reveals that there exists a robust relationship between teachers' knowledge and implementation of DI (Brentnall, 2016; McMillan, 2011) and also between teachers' sense of efficacy and implementation DI (Brentnall, 2016; De Neve et al., 2015; Dixon et al., 2014). Moreover, prevailing evidence from literature suggests that there are significant differences in teachers' implementation of DI strategies based on their teaching qualification and experience (Garrett, 2017; Suprayogi et al., 2017). 


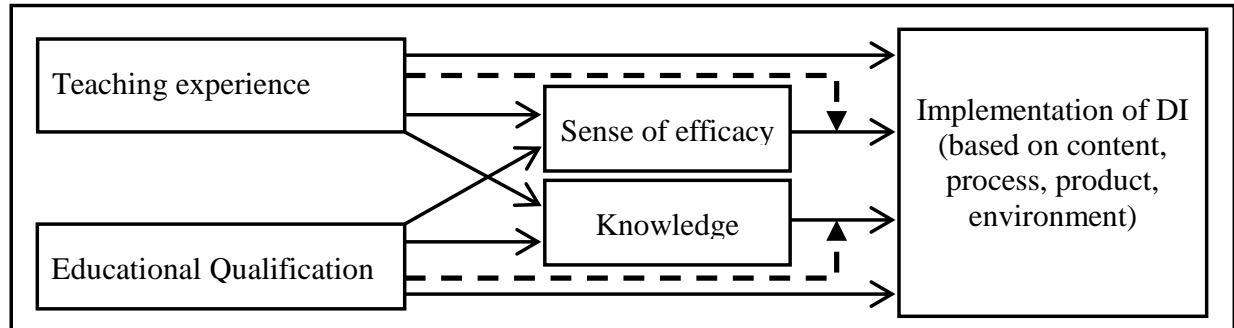

Figure 1

Conceptual framework of the study

Figure 1, thus, shows the diagrammatic representation of the conceptual framework, which in essence, depicts the hypothesized relationships that are to be tested in the current study. As portrayed in Figure 1, it is postulated that (i) teachers' knowledge and sense of efficacy have an impact on their implementation of DI; (ii) teachers' knowledge, efficacy and implementation of DI are influenced by their qualification and teaching experience; (iii) the relationship between teachers efficacy, knowledge and implementation of DI is moderated by teachers' experience and qualification

\section{Knowledge and Implementation of DI}

The vast majority of existing research shows strong evidence of the positive relationship between teachers' knowledge and implementation of DI. Previous researches assumed that teachers' knowledge of DI would have a significant impact on their implementation of the strategies. According to Nedellec (2015) a major factor for teachers' irregular and inconsistent use of the strategies is their lack of accurate pedagogical content knowledge of DI. Moreover, the regression analysis employed by McMillan (2011), involving 79 middle school teachers, revealed that teachers' implementation of DI strategies by content, process, and product is related to their familiarity (knowledge and understanding) with the concept.

Previous studies have also investigated teachers' engagement in acquiring professional knowledge in relation to their DI implementation. For instance, Baxter's (2013) mixed method study involving 75 teachers revealed that the training had a positive impact on teachers' attitudes, knowledge and implementation of DI. Similarly, Brentnall (2016) also investigated the relationship between teachers' perception on the training they received on DI and the extent to which they use strategies of DI in their classrooms. By synthesizing data that was gathered using a handful of techniques, the researcher concluded that there was an overall positive impact of the training on teachers' ability to use DI strategies. These findings, hence, suggest that teachers' knowledge and implementation of DI are positively related.

\section{Efficacy and Implementation of DI}

With regard to teachers' general sense of efficacy, existing literature shows strong empirical evidence that there is a strong relationship between teacher's sense of efficacy and instructional strategies adopted by teachers (Holzberger et al., 2013). This is 
supported by previous finding that teachers with higher levels of efficacy view that they are more prepared to differentiate instruction as compared to those with lower levels efficacy (Johnson, 2010). More specifically, Casey (2011), using a two-phase, sequential mixed-methods design, investigated 36 novice teachers' perceptions on how prepared and efficacious they are to use DI. The study revealed that self-efficacy and perceived level of preparedness for differentiation are correlated positively with a very large effect size.

The association between teachers' sense of efficacy and implementation of DI is not only relational but also predictive. For instance, Dixon, Yssel, McConnell, and Hardin (2014) conducted a quantitative research involving 45 teachers from five different schools (including elementary, middle and high schools) that belong to two schools districts of varied characteristics. The study found that teacher sense of efficacy and teacher efficacy were both strong predictors of implementation of DI. De Neve et al.'s (2015) quantitative study also revealed similar findings. Analyses of data from a relatively large sample size of 227 novice teachers from 65 elementary schools indicated teachers' self-efficacy was a significant predictor of changes in DI practices.

\section{Demographic Factors}

Existing research informs the association between a number of demographic factors and teachers' efficacy, knowledge and implementation of DI. These include class size, teaching level, teachers' qualification, and teaching experience. Among these, teachers' experience and qualification have been investigated in a number of previous studies (see Casey, 2011; Crum, 2004; Dixon et al., 2014; Garrett, 2017; McMillan, 2011; Suprayogi et al., 2017).

With respect to teaching experience, the majority of the existing research reports a positive association between teachers' experience and DI implementation. Garrett (2017), for instance, conducted a quantitative research using a causal comparative design to investigate the difference among teachers in their efficacy about DI and the frequency in which DI is implemented. The findings showed that there was a significant difference in self-efficacy and frequency in which DI was implemented based on teachers' experience. The difference was evident between those in the first year of teaching and those who have already worked for more than one year.

Likewise, a very recent and relatively large quantitative study by Suprayogi et al. (2017) is in robust support of the above finding. With a sample size of 604 teachers who were chosen from 145 randomly selected schools Suprayogi and colleagues (2017) found that the level of teaching experience reflected significant differences in implementation of DI between teachers with more than five years of experience compared to those who have acquired less experience. Similar findings were also reported by earlier studies where it was found that teachers knowledge and experience were rated the top factors to enabling the implementation of DI (Chien, 2015; Rodriguez, 2012).

On other hand, there are few studies that reported findings contrary to the above. In this regard, McMillan (2011) reported that teaching experience in terms of number of years did not show a significant relationship with teachers' use of DI. McMillan (2011) 
however, acknowledged the non-significant contribution of experience to implementation of DI reporting that teaching experience explained $6.1 \%$ of the variance in use of DI. Other studies reported non-significant differences in teachers' efficacy for differentiation rather than actual implementation of the strategies (Crum, 2004; Dixon et al., 2014).

With regard to teachers' qualification, it is observed that this variable is rarely investigated as compared to teachers' experience. The few studies that were available to refer in the review of literature collectively report a positive association between teachers' qualification and implementation of DI. For instance, McMillan (2011) reported that teachers' education levels had an overall positive association with teachers' use of DI. As stated by the researcher, $10 \%$ of the variance in differentiating instructions can be explained by teachers' educational levels. Similarly, Suprayogi et al. (2017) found that teachers with a teaching certification reported significantly higher levels implementation of DI as compared to teachers without one. Finally, according to Casey (2011), teachers with many certifications tended to feel more prepared and poised to use DI among varied learners.

\section{The Need for The Study}

As explicated, previous studies have identified that teachers' knowledge of DI and their sense of efficacy have a positive impact on their implementation of DI strategies (De Neve et al., 2015; Holzberger et al., 2013; Johnson, 2010; McMillan, 2011; Nedellec, 2015). Additionally, existing research also suggests that teachers' experience in teaching and their level of qualification might also influence their sense of efficacy and implementation of DI (Chien, 2015; Garrett, 2017; McMillan, 2011; Suprayogi et al., 2017). However, previous studies failed to investigate the effect of these demographic variables on the relationship between teachers' knowledge of DI, their sense of efficacy and their implementation of DI.

Hence, the purpose of this quantitative study is to investigate the differences in teachers' sense of efficacy, knowledge and implementation of DI based on their experience and qualification. Additionally, the study also aims to investigate the moderating effects of teachers' experience and qualification on the impact of teachers' efficacy and knowledge on implementation of DI. Subsequently, the following research questions were devised, in order to fulfill the purpose of the study.

1. Is there any difference in teachers' sense of efficacy based on their experience in teaching and qualification?

2. Is there any difference in teachers' knowledge of differentiated instruction based on their experience in teaching and qualification?

3. Is there any difference in teachers' implementation of differentiated instruction based on their experience in teaching and qualification?

What is the effect of demographic variables (experience in teaching and qualification) on the relationship between teachers' sense of efficacy, knowledge, and implementation of differentiated instruction? 


\section{METHOD}

Since the study involves testing of presumed hypotheses, it is guided by the postpositivist philosophies in social science research. Of the various research designs which fall under the chosen research paradigm, a cross-sectional field survey design is deemed appropriated since data is collected at one point in time to identify participants' knowledge, beliefs, and practices (Creswell, 2012). A field survey is chosen to increase the return rate and accuracy of data collected.

\section{Participants}

The target population for the study was elementary teachers in a single atoll of Maldives. The table provided by Krejcie and Morgan (1970) was used for determining the sample size in this study. As there were a total of 120 primary teachers in the atoll, a sample size of 92 would be adequate, according to the table, for a confidence interval of $95 \%$ with 5\% error (two-tailed). The survey was distributed to all teachers adhering to the principles of total population sampling out of which 101 completed surveys were returned back. Nevertheless, there were variations in sample sizes for certain analyses due to missing data and the choice of pair-wise deletion made during the analyses. Table 1 shows the actual number of cases used with details of the group sizes that were engaged in the analyses. As indicative in the table, distribution of participants into the groups is appropriate to conduct the required statistical analyses.

Table 1

Participants' Demographic Information

\begin{tabular}{llll}
\hline Demographic variables & Categories & $\mathrm{n}$ & $\%$ \\
\hline \multirow{2}{*}{ Teaching experience } & Less than 8 yrs & 32 & 33.33 \\
& 8 to 12 yrs & 32 & 33.33 \\
\multirow{3}{*}{ Qualification } & More than 12 yrs & 32 & $33.34^{*}$ \\
& Degree and above & 59 & 59.00 \\
& Diploma and below & 41 & 41.00 \\
\hline
\end{tabular}

* Adjusted to add-up to $100 \%$.

\section{Survey Instrument}

The survey is consisted of three sections; Section A on demographics, Section B on knowledge and implementation; and Section $\mathrm{C}$ on teacher efficacy. All the items in Section B and C are taken from pre-validated tools that were employed in previous researches. In this regard, all the items for the knowledge and implementation scales (Section B) were taken from Davis (2013) and McMillan (2011) while all the items for the teacher efficacy scale (Section C) were taken from Tschannen-Moran and Hoy (2001). Each item in section B are required to be rated on two different scales; that is, the same item is supposed to be rated twice, once on the knowledge scale and then on the implementation scale. The statements fall under four categories, as informed by the theoretical framework; content, process, product and environment. An example item on the content subscale reads as "I provide all students with a variety of reading materials at different reading levels". 
The respondents were first required to rate this statement based on their knowledge using a five-point Likert scale ranging from one (1) "I am not familiar with this strategy" to five (5) "I am very familiar with this strategy". Next, the respondents were required to rate the same statement based their implementation, using a different fivepiont Likert scale where one (1) corresponds to "Never" to five (5) corresponds to "Frequently". Items in Section C, which measure teachers' efficacy beliefs, are all on a nine-point Likert scale which ranges from one (1) representing that the participants can do "Nothing" regarding the stated behavior to nine (9) representing that the participants can do a "Great deal" regarding it. Items in the efficacy scale are given in the form of questions as opposed to statements. A sample item from the scale reads as "How much can you do to control disruptive behavior in the classroom?"

\section{Data Analysis}

Participants' responses to the questionnaire items as well as the demographic information collected were coded and entered into SPSS 21.0 which was employed to analyze the data and assess the assumed hypotheses. Prior to data analyses, the data were screened for the extent of missing data which warranted action. It is because, simply deleting the missing values would reduce the sample size substantially, thereby inhibiting the possibilities of carrying out the intended analyses. Assessment of the pattern of the missing data, using Little's MCAR test, revealed that the data is Missing Completely At Random. When the data is MCAR, any plausible methods of replacing missing values may be used (Hair, Black, Babin, \& Anderson, 2014). Subsequently, missing data in the present study were replaced with mean values.

Additionally, the dependent variables were examined using skewness and kurtosis statistics to ensure if the data did not significantly deviate from normality. The maximum and minimum values for the skewness statistic were 0.0 and -2.0 which are within the range (-2 to 2) of suspectful deviation from normality (Cain, Zhang, \& Yuan, 2016; Curran, West, \& Finch, 1996). Similarly, the kurtosis statistic ranged from -0.8 to 4.9 which is within the boundary (-7 to 7) of doubtful deviance from normality (Curran et al., 1996). As such, it was found that data deemed appropriate for parametric statistical analyses. Accordingly, the specific tests that were utilized in testing the hypotheses are independent sample $t$-test, one-way ANOVA, and multiple regression. Detailed procedures of these are given when presenting the respective findings.

\section{Validity and Reliability}

All the items in section B and C of the survey questionnaire were taken from previous studies whereby the respective researchers reported the validity and reliability of the items as well as the scales. Since, these items were reported to have obtained content and construct validity, the procedures for doing so were not repeated. However, the scales were assessed for reliability in the context of the study where Cronbach alpha for the knowledge, implementation, and efficacy scale were $.953, .942$, and .922 . Hence, all the scales achieved very good internal consistency (Pallant, 2007). 


\section{FINDINGS}

The study was guided by four research questions. As such, the findings reported here are organized in the order in which the research questions appear in this paper. The first research question aims to investigate if there is a significant difference in teachers' sense of efficacy with regards to their experience and qualification. Two types of statistical procedures were employed in answering this research question.

First, one-way ANOVA was used to see if there is a significant difference in teachers' sense of efficacy with regards to their experience in teaching (as the variable had more than two categorical groups). In order to do the analysis, subjects were divided into three groups based on the years of teaching experience (Group 1: less than 8 years; Group 2: between 8 to 12 years; Group 3: more than 12 years). The results (see Table 2) revealed that there is a statistically significant difference at the $p<.05$ level in teachers' sense of efficacy for the three groups; $F(2,93)=3.56, p=.032$. Furthermore, the actual difference in mean scores is classified as medium as indicated by $\mathrm{D}^{2}$ of .071 (Cohen, 1988). Post-hoc comparison using Tukey HSD test showed that the mean scores for Group $1(M=85.20, S D=11.78)$ was significantly different from Group $2((M=91.93$, $S D=10.06)$. Group $3(M=91.45, S D=11.84)$ did not differ significantly from either Group 1 or 2.

Table 2

Difference in Teacher Sense of Efficacy by Experience

\begin{tabular}{|c|c|c|c|c|c|c|c|c|c|c|}
\hline \multirow{2}{*}{$\begin{array}{l}\text { Teaching } \\
\text { Experience }\end{array}$} & \multirow{2}{*}{$\mathrm{n}$} & \multirow{2}{*}{ Mean } & \multirow{2}{*}{ SD } & \multirow{2}{*}{ SE } & \multicolumn{2}{|c|}{$\begin{array}{l}95 \% \text { CI for } \\
\text { Mean }\end{array}$} & \multirow{2}{*}{$\mathrm{F}$} & \multirow{2}{*}{ df } & \multirow{2}{*}{ Sig } & \multirow[t]{2}{*}{$n^{2}$} \\
\hline & & & & & Lower & Upper & & & & \\
\hline Less than 8 yrs & 32 & 85.20 & 11.78 & 2.08 & 80.95 & 89.45 & 3.56 & 2,93 & $.032 *$ & .071 \\
\hline 8 to $12 \mathrm{yrs}$ & 32 & 91.93 & 10.06 & 1.78 & 88.30 & 95.56 & & & & \\
\hline More than 12 yrs & 32 & 91.45 & 11.84 & 2.09 & 87.18 & 95.72 & & & & \\
\hline Total & 96 & 89.53 & 11.56 & 1.18 & 87.18 & 91.87 & & & & \\
\hline
\end{tabular}

Notes: $* p<.05 ; \mathrm{SE}$, standard error of mean; $\mathrm{D}^{2}$, Eta squared (effect size) calculated by formula: sum of squares between-groups / total sum of squares

Independent sample $t$-test was conducted to examine the difference in teachers' sense of efficacy with respect to the second demographic variable of teachers' qualification (as the variable had two categorical groups). Group 1 consisted of teachers with degree and above certifications while Group 2 consisted of those with diploma and below certifications. The results of the test, as given in Table 3 indicate that the there was no significant difference at $p<.05$ level in mean for Group $1(M=88.24, S D=13.59)$ and Group $2(M=90.57, S D=9.94) ; t(98)=-1.00, p=.32$. The magnitude of difference is trivial (mean difference $=-2.32,95 \%$ CI: -6.92 to 2.27 ) as indicated by $\mathrm{D}^{2}=.001$ (Cohen, 1988). 
Table 3

Difference in Teacher Sense of Efficacy by Qualification

\begin{tabular}{|c|c|c|c|c|c|c|c|c|c|}
\hline \multirow{2}{*}{ Qualification } & \multirow{2}{*}{$\mathrm{n}$} & \multirow{2}{*}{ Mean } & \multirow{2}{*}{ SD } & \multirow{2}{*}{ SE } & \multicolumn{2}{|c|}{$95 \%$ CI for Mean } & \multirow{2}{*}{ df } & \multirow{2}{*}{ Sig } & \multirow{2}{*}{$\mathrm{n}^{2}$} \\
\hline & & & & & Lower & Upper & & & \\
\hline Degree and above & 59 & 88.24 & 13.59 & 1.76 & 84.72 & 91.77 & -1.0098 & .32 & .001 \\
\hline $\begin{array}{l}\text { Diploma and } \\
\text { below }\end{array}$ & 41 & 90.57 & 9.94 & 1.50 & 87.53 & 93.61 & & & \\
\hline Total & 100 & 89.20 & 12.09 & 1.21 & 86.80 & 91.60 & & & \\
\hline
\end{tabular}

Two types of statistical tests were used to answer the second and third research questions; one-way ANOVA was used to investigate the differences in teachers' knowledge and implementation of DI based on their experience, while independent sample $t$-test was employed for studying the same based on teachers' qualification. Results of ANOVA indicated that there is no statistically significant difference in teachers' knowledge as well as implementation of DI based on their experience. The mean scores (and standard deviations) for knowledge by experience Groups 1, 2 and 3 were $M=151.08(S D=15.41), M=150.86(S D=16.13)$, and $M=148.18(S D=$ 22.66). The same for implementation were $M=133.79$, $(S D=16.91), M=139.56$ ( $S D$ $=19.13)$, and $M=134.47(S D=22.74)$ respectively.

Similarly, the results of the $t$-tests indicated that there is no significant difference in teachers' knowledge of DI between more qualified $(M=147.51, S D=20.35)$ and less qualified $(M=152.88, S D=14.45)$ teachers, $t(98)=-1.54, p=.13$. Additionally, it is also found that there is no significant difference in teachers' implementation of DI between more qualified $(M=135.23, S D=19.82)$ and less qualified $(M=137.17, S D=$ 19.41) teachers, $t(98)=-0.49, p=.63$.

The last research question was answered by employing multiple regression. It is postulated that implementation of DI (dependent variable, DV) is predicted by teachers' knowledge and efficacy (independent variables, IVs). In order to answer the research question, the model was tested for the moderation effect of the two demographic variables of experience and qualification by splitting the data into respective groups. In this regard, the data file was first split (using the appropriate function in SPSS) into the three groups of experience used in previous analyses. Split analysis was preferred in this study as the objective was to test the moderation based on the overall fit of the regression model as opposed to testing the effect on individual predictors. The regression analysis was then run by entering all the variables (IVs and DV) into the equation, the results of which are shown in Table 4. As can be drawn from Table 4, the $R^{2}$ values for the models generated for each of the three groups are different (Group $1=$ .242 , Group $2=.439$, Group $3=.378$ ). 
Table 4

Multiple Regression Analysis by Experience

\begin{tabular}{lllllll}
\hline Model $^{\mathrm{a}}$ & $\mathrm{F}$ & $\mathrm{df}$ & $\mathrm{R}$ & $\mathrm{R}^{2}$ & $\mathrm{AdjR}^{2}$ & $\mathrm{SE}$ \\
\hline Group 1 & $4.64^{*}$ & 2,29 & .492 & .242 & .190 & 15.22 \\
Group 2 & $11.34^{* *}$ & 2,29 & .662 & .439 & .400 & 14.81 \\
Group 3 & $8.80^{* *}$ & 2,29 & .615 & .378 & .335 & 18.54 \\
\hline
\end{tabular}

Notes: ${ }^{a}$ predictors (constant), knowledge, efficacy; SE, standard error of estimates.

$* p<.1, * * p<.001$

In order to determine if there is a significant difference in model fit $\left(R^{2}\right)$ between the groups, Fisher's $Z$ Test (FZT) was performed by entering the $R$ values into the test to obtain the $Z$ scores (Fisher, 1921) and associated $p$ values. The procedure for transforming $r$ (in this case $R$ ) to $r^{\prime}$ and the then computing the $Z$ statistic has been explained by Weaver and Wuensch (2013). This study engaged the calculator provided at (www.psychometrica.de) for the above purpose. Prior to the use, the calculator was checked against the mentioned procedure to confirm the reliability of the results. Correlation coefficients $(R)$ for the groups were then entered into the FZT calculator in pairs. Analyses of the FZT revealed that there was no significant difference in the overall model fit (variance explained by the models). Thus, experience is not a significant moderator of DI implementation.

Similar procedures as above were employed to investigate the moderation effect of qualification. Table 5 depicts the results of the regression analysis of the models run for the two groups. As can be drawn from Table 5, the $R^{2}$ values for the models generated for each of the three groups are different (Group $1=.415$, Group $2=.383$ ). However, analyses of the FZT revealed that there is no significant difference between the model fit for the two groups. Thus, qualification is not a significant moderator of DI implementation.

Table 5

Multiple Regression Analysis by Qualification

\begin{tabular}{lllllll}
\hline Model $^{\mathrm{a}}$ & $\mathrm{F}$ & $\mathrm{df}$ & $\mathrm{R}$ & $\mathrm{R}^{2}$ & $\mathrm{AdiR}^{2}$ & $\mathrm{SE}$ \\
\hline Group 1 & $19.85^{*}$ & 2,56 & .644 & .415 & .394 & 15.43 \\
Group 2 & $11.77^{*}$ & 2,38 & .618 & .383 & .350 & 15.65 \\
\hline
\end{tabular}

Notes: ${ }^{a}$ predictors (constant), knowledge, efficacy; SE, standard error of estimates; $* p<.001 .$.

\section{DISCUSSION}

One of the purposes of the present study was to investigate how the demographic variable of teachers' experience and qualification explain differences in teachers' sense of efficacy, knowledge and implementation of DI. To investigate the moderating effect of the demographic variables on the relationship between their sense of efficacy, knowledge and implementation of DI was the second purpose of the study. The discussion begins with the findings relevant to the first research objective and is sequenced in the order of the research questions. 
In this regard, for the first research question, it was found that teacher's sense of efficacy between the least-experienced group and the other two groups differ significantly. Furthermore, observations of the median scores confirmed that more experienced teachers generally have stronger efficacy beliefs as compared to the less experienced. The findings of this study are supported by previous studies which reported significant differences in self-efficacy based on teaching experience. Garrett (2017), for instance, argued that such differences in efficacy beliefs are evident from a very early stage of teaching career. Similarly, Tschannen-Moran and Woolfolk (2007), using the same efficacy scale used in this study, found that experienced teachers in their sample had higher self-efficacy beliefs than the novice teachers, giving support to the present findings. With regard to the second demographic variable of qualification it was found that teachers' efficacy beliefs were not significantly different based on their qualification. However, the present finding is supported by Casey (2011) where the researcher stated that there were no significant differences between teachers with two or three certifications with regard to perceived levels self-efficacy to differentiate instruction.

The theory of self-efficacy can largely explain the difference in teachers' efficacy beliefs with regards to experience and qualification. While qualification can improve one's ability in performing a task, it may not necessarily increase the belief that he or she can perform the same. According to Bandura (1977), the concept of mastery learning, which explains how one's efficacy beliefs either increase or decrease depending on his or her experience in performing a given task, is the strongest source of efficacy beliefs. Successful attempts in performing something generally improve efficacy beliefs while continued failures to do the same weaken those beliefs (Bandura, 1997). Hence, teachers' experience in teaching can explain some of the differences in their efficacy beliefs toward teaching. Similarly, teachers' qualification may not show any difference in their efficacy due to its dependency on positive experience.

With regards to the second research question, it was found that there is no significant difference in teachers' knowledge of DI when compared against their experience or qualification. Although previous studies have not investigated how teachers' knowledge of DI differ based on their teaching experience and qualification, the results showed that this is an important aspect to be examined. It is claimed that knowledge of specific teaching strategies such as DI does not necessarily increase with the amount of experience teachers accumulate by simply working as a teacher for many years. The results also reveal that teachers do not essentially advance knowledge of DI with respect to the number or level of qualifications they obtain. Arguably, it is the content of the training programs leading to these certifications that matters. Hence, provision of specific knowledge of DI is important given the complexity of the strategies (Tomlinson, 1999).

Previous studies indicate that training or professional development provided to teachers may not cover sufficient amount of content on DI. For instance, Suprayogi et al. (2017), after analyzing the experiences of professional development as reported by teachers, concluded that the trainings did not contain any explicit content focused on DI. In 
addition to this, the researchers also raised concerns that a many teachers in the study did not even attend to any form of teacher training. Hence, it is argued that it is the specific pedagogical content knowledge - not simply experience and qualification - that matter when it comes to teachers' knowledge of such strategies.

Similar findings were obtained for the third research question, which asked about the implementation of DI. There was no significant difference in teachers' implementation of DI either based on their experience or qualification. Previous studies, however, reported mixed findings regarding implementation of DI with respect to these variables. On experience, while some studies report no relationship between years of teaching experience and use of DI (McMillan, 2011), others found that there is a significant difference in DI implementation between less experienced and more experienced teachers (Garrett, 2017). With regards to teachers' qualification and implementation of DI, majority of the consulted literature reported significant differences in implementation of DI based on teachers' qualification (McMillan, 2011). Thus, the results of the current study are in contradiction with the majority of the existing findings.

While the present study did not find a significant difference in implementation of DI based on either of the two variables, Suprayogi et al.'s (2017) study, for instance, found a significant difference for both of them. It is assumed that the difference in teachers' implementation of DI could be more due to their qualification which incorporated some training (knowledge) on DI. As such, the significant difference observed in those studies might not necessary be on account of either experience or qualification, rather an interplay of both, or perhaps, influenced by a third factor. Furthermore, the results suggest that it may be false to assume that teachers' use of teaching strategies like DI increases as they continue more years on the job. It is claimed that use of such innovative teaching strategies does not naturally happen as a result of daily encounters in teachers' work. Rather, it is the result of purposeful endeavors associated with appropriate knowledge and intention to really implement it that could enhance the use of such strategies as emphasized in the theory of planned behavior (Ajzen, 1985, 1988; Ajzen \& Fishbein, 1980).

The second aim of the present study was to investigate the moderating effect of teachers' experience and qualification on the relationship between teachers' efficacy, their knowledge and implementation of the DI strategies. The regression analysis for the three experience groups showed that teachers' experience is not a significant moderator of their implementation of DI. This indicates that the impact of both knowledge and efficacy does not change with experience despite the significant difference in efficacy observed for the same variable. It is because, teaching experience, per say, might not be enough to explain a significant positive difference in DI implementation. Rather it is how the multiple facets of teaching are 'experienced' by the individual which may bring in a real difference in such practices (Bandura, 1997).

With regard to the second demographic variable of teachers' qualification, it was found that it is not a significant moderator of DI implementation in the tested model. This is again of little surprise since it was already found that teachers' qualification does not bring in any difference in their knowledge and implementation of DI in this study. As 
there exists a strong relationship between knowledge of DI and its implementation (Baxter, 2013; Brentnall, 2016; McMillan, 2011) the possible explanation for qualification not showing any significant difference on knowledge and implementation of DI is that those qualifications might not be consisted of adequate content on DI (Jenkins \& Yoshimura, 2010; Suprayogi et al., 2017).

\section{CONCLUSIONS AND RECOMMENDATIONS}

The present investigation was guided by two basic purposes; firstly, to investigate the differences in teachers' sense of efficacy, their knowledge and implementation of DI based on their experience and qualification; and secondly, to investigate the moderating effect of teachers' experience and qualification on the relationship between their efficacy and knowledge, and implementation of DI. It was found that most of the dependent variables were not significantly different based on the demographic variables that were investigated in this study. Similarly, none of the demographic variables had significant moderating effect on the regression model. On the contrary, teacher efficacy was known to differ significantly by experience. A number of conclusions were made with reference to these findings.

Firstly, it is concluded that the difference in teachers' efficacy can largely be explained by their experience. As such, in order to raise efficacy beliefs, teachers must encounter positive and encouraging experiences in their daily teaching endeavors. Subsequently, teachers must get the opportunity to apply their knowledge and master it in order to feel more efficacious. Secondly, although qualification may play a vital role in efficacy beliefs, only those qualifications with appropriate knowledge of the construct being measured may improve such beliefs. Thirdly, it is concluded that knowledge of DI does not necessarily increase with number of years of teaching experience, nor with the number or level of qualifications obtained by teachers. It is only those qualifications which are composed of relevant pedagogical knowledge of DI along with the chance to practice differentiation in everyday teaching that might bring a difference. Finally, it is concluded that, in order to examine the true influence of the demographic variables, it is required to explore the nature of experience teachers gain and the composition of the training programs that lead to various qualifications.

The above conclusions lead to the following recommendations to policy, practice and research. Firstly, teacher qualification did not show any significant difference in knowledge of DI indicating teachers' lack of knowledge as identified by VanTasselBaska and Stambaugh (2005). Hence, it is recommended that existing teachers should be provided with appropriate and sufficient knowledge about it. Secondly, the findings suggest that the training programs may not contain enough content of DI. Existing research claims that pre-service trainings for general education certification usually do not include detailed instruction on how to teach wide ranges of learners (Jenkins \& Yoshimura, 2010). Thus, it is recommended to revise such training programs to incorporate adequate focus on DI. Thirdly, in order to increase teachers' efficacy beliefs, it is crucial that schools provide avenues for boosting those beliefs. Providing various forms of support for implementation of DI may be helpful in this regard. Finally, it is suggested that research on teachers' implementation of DI require higher levels of 
statistical analysis. Utilizing structural equation modeling grounded in Ajzen's (1985) theory of planned behavior may be a way forward for future studies.

\section{LIMITATIONS}

The present study is constrained by the following limitations. Firstly, although the study engaged a reasonably good sample size, the samples for the split analyses were limited in number. Hence, replication of the study with a much bigger sample is required to confirm the results of the present study. Secondly, this study used the overall model fit as a basis for comparison among groups for moderation analysis. As a result, it is unable to comment on the effect of the individual predictors of the model. Future studies may, instead, employ interaction terms to address this shortcoming. Finally, the validity of the findings is limited to the way in which experience and qualification were measured in this study. Future studies can collect data on specific experience on using DI and also qualification with some training of the strategies.

\section{REFERENCES}

Ajzen, I. (1985). From intentions to actions: A theory of planned action. In J. Kuhl \& J. Beckman (Eds.), Action control: From cognition to behaviour (pp. 11-39). New York: Springer.

Ajzen, I. (1988). Attitudes, personality, and behaviour. Milton Keynes, UK: Open Univeristy Press.

Ajzen, I., \& Fishbein, M. (1980). Understanding attitudes and predicting social behaviour. Englewood Cliffs, NJ: Prentice Hal.

Bandura, A. (1977). Self-efficacy: Toward a unifying theory of behavioral change. Psychological Review, 84(2), 191-215.

Bandura, A. (1997). Self-efficacy: The exercise of control. New York: W. H. Freeman and Company.

Baxter, J. D. (2013). How teacher training affects the implementation of differentiated instruction at the elementary level. (Doctoral Dissertation). Available at ProQuest Thesis and Dissertations. (UMI: 3551590).

Brentnall, K. (2016). Believing everyone can learn: differentiating instruction in mixed ability classrooms. (Doctoral Dissertation). College of Saint Elizabeth.

Cain, M. K., Zhang, Z., \& Yuan, K.-H. Y. (2016). Univariate and multivariate skewness and kurtosis for measuring nonnormality: Prevalence, influence and estimation. Behavior Research Methods, 49, 1716-1735. https://doi.org/10.3758/s13428-016-08141 Univariate

Casey, M. (2011). Perceived efficacy and preparedness of beginning teachers to differentiate instruction. (Doctoral Dissertation). Available from ProQuest Dissertation and Thesis. (UMI 3450193).

Chien, C.-W. (2015). Analysis of Taiwanese elementary school English teachers' 
perceptions of, designs of, and knowledge constructed about diffrentiated instruction in content. Cogent Education, 2, 1-16.

Cohen, J. (1988). Statistical Power Analysis for the Behavioral Sciences (2nd ed.). USA: Lawrence Erlbaum Associates.

Creswell, J. W. (2012). Educational research: Planning, conducting and evaluating quantitative and qualitative research (4th ed). Boston: Pearson Education, Inc.

Crum, P. A. (2004). Instructional methods and efficacy of teachers trained in differentiated instruction. (Doctoral Dissertation). Available from ProQuest Dissertations \& Theses Global. (UMI No. 3175884).

Curran, P. J., West, S. G., \& Finch, J. F. (1996). The robustness of test statistics to nonnormality and specification error in confirmatory factor analysis. Psychological Methods, 1(1), 16-29.

Davis, T. C. (2013). Differentiation of instruction in regular education elementary classes: An investigation of faculty and educational leaders' perceptions of differentiated instruction in meeting the needs of diverse learners. (Doctoral Dissertation). Available at ProQuest Thesis and Dissertations. (UMI: 3589970).

De Neve, D., Devos, G., \& Tuytens, M. (2015). The importance of job resources and self-efficacy for beginning teachers' professional learning in differentiated instruction. Teaching and Teacher Education, 47, 30-41.

Dixon, F. A., Yssel, N., McConnell, J. M., \& Hardin, T. (2014). Differentiated instruction, professional development, and teacher efficacy. Journal for the Education of the Gifted, 37(2), 111-127.

Fisher, R. A. (1921). On the probable error of a coefficient of correlation an found from a small sample. Metron. https://doi.org/10.1093/biomet/9.1-2.22

Garrett, S. (2017). A Comparative Study between Teachers' Self-Efficacy of Differentiated Instruction and Frequency Differentiated Instruction is Implemented. (Doctoral Dissertation). Available from ProQuest Dissertations \& Theses. (Order No. 10257026).

Hair, J. F., Black, W. C., Babin, B. J., \& Anderson, R. E. (2014). Multivariate Data Analysis (7th ed.). Edinburgh: Pearson Education Limited.

Holzberger, D., Philipp, A., \& Kunter, M. (2013). How teachers' self-efficacy is related to instructional quality: A longitudinal analysis. Journal of Educational Psychology, 105(3), 774-786.

Jenkins, A., \& Yoshimura, J. (2010). Not another inservice! Meeting the special education professional development needs of elementary general educators. Teaching Exceptional Children, 42(5), 36-43.

Johnson, D. (2010). Learning to teach: The influence of a university-school partnership project on pre-service elementary teachers' efficacy for literacy instruction. Reading 
Horizons, 50(1), 23-48.

Joseph, S., Thomas, M., Simonette, G., \& Ramsook, L. (2013). The impact of differentiated instruction in a teacher education setting: Successes and challenges. International Journal of Higher Education, 2(3), 28-40.

Krejcie, R. V, \& Morgan, D. W. (1970). (1970). Determining sample size for research activities. Educational and Psychological Measurement, 30(3), 607-610.

Lange, K. (2009). Lessons learned in an inclusive classroom: A case study of differentiated instruction. (Doctoral Dissertation). Available from ProQuest Dissertations \& Theses. (Order No. 3385161).

Logan, B. (2011). Examining differentiated instruction: Teachers respond. Research in Higher Education Journal, 13, 1-15.

McMillan, A. (2011). The relationship between professional learning and middle school teachers' knowledge and use of differentiated instruction. (Doctoral Dissertation). Walden University.

Morrison-Thomas, N. (2016). Exploring teachers' experiences of differentiated instruction: A qualitative case study. (Doctoral Dissertation). Available from ProQuest Dissertations \& Theses. (Order No. 10140347).

Nedellec, C. M. (2015). Teachers' understanding of differentiated instruction in Swiss elementary schools. (Doctoral Dissertation). Available from ProQuest Dissertations \& Theses. (Order No. 3718012).

Pallant, J. (2007). SPSS survival manual. Berkshire, England: Open University Press.

Reis, S. M., Mccoach, D. B., Little, C. A., Muller, L. M., \& Kaniskan, R. B. (2011). The effects of differentiated instruction and enrichment pedagogy on reading achievement in five elementary schools. American Educational Research Journal, 48(2), 462-501.

Ricketts, M. A. (2014). The lived experiences of teachers in implementing differentiated instruction in the inclusive classroom. (Doctoral Dissertation). Available from ProQuest Dissertations \& Theses. (Order No. 3645551).

Robinson, Q. E. (2017). Perceptions and adoption of differentiated instruction by elementary teachers. (Doctoral Dissertation). Available from ProQuest Dissertations \& Theses. (Order No. 10255701).

Rockinson-Szapkiw, A. J. (2017). Research categories and designs. Retrieved April 24, 2017 ,

http://drrockinsonszapkiw.com/elearning/quantitativeresearchguide/content/index.html

Rodriguez, A. (2012). An Analysis of elementary school teachers' knowledge and use of diffrentiated instruction. (Doctoral Dissertation). Available from Ed.D. Dissertationsl. (Paper 39).

Ruys, I., Defruyt, S., Rots, I., \& Aelterman, A. (2013). Differentiated instruction in 
teacher education: A case study of congruent teaching. Teachers and Teaching: Theory and Practice, 19(1), 93-107.

Santangelo, T., \& Tomlinson, C. A. (2012). Teacher educators' perceptions and use of differentiated instruction practices: An exploratory investigation. Action in Teacher Education, 34, 309-327.

Siam, K., \& Al-Natour, M. (2016). Teacher's differentiated instruction practices and implementation challenges for learning disabilities in Jordan. International Education Studies, 9(12), 167.

Suprayogi, M. N., Valcke, M., \& Godwin, R. (2017). Teachers and their implementation of differentiated instruction in the classroom. Teaching and Teacher Education, 67, 291-301.

Tomlinson, C. A. (1999). Personalized learning: Mapping a route toward differentiated instruction. Educational Leadership, 57(1), 12-16.

Tomlinson, C. A. (1999). The differentiated classroom: Responding to the needs of all learners. Alexandria, Va: Association for Supervision and Curriculum Development.

Tomlinson, C. A. (2000). Differentiation of Instruction in the Elementary Grades. ERIC Digests, 1-7.

Tomlinson, C. A. (2001). Differentiated instruction in the regular classroom: What does it mean? How does it look? Understanding Our Gifted, 14(1), 3-6.

Tomlinson, C. A. (2008). Differentiated instruction. In J. Plucker \& C. Carolyn (Eds.), Critical issues and practices in gifted education: What the research says (2nd ed). USA: National Association for Gifted Children.

Tomlinson, C. A. (2014). The differentiated classroom: Responding to the needs of all learners. Alexandria, VA: ASCD.

Tomlinson, C. A., Brighton, C., Hertberg, H., Callahan, C. M., Moon, T. R., Brimijoin, K., ... Reynolds, T. (2003). Differentiating instruction in response to student readiness, interest, and learning profile in academically diverse classrooms: A review of literature. Journal for the Education of the Gifted, 27(2/3), 119-145.

Tomlinson, C. A., \& Imbeau, M. B. (2014). Leading and managing a differentiated classroom. Virginia: ASCD Publications.

Topley, B. M. (2010). Professional development implementation: Perceptions of elementary and middle-school teachers and administrators. (Doctoral Dissertation). Available from ProQuest Dissertations \& Theses. (Order No. 3455225).

Tschannen-Moran, M., \& Hoy, A. W. (2001). Teacher efficacy: Capturing an elusive

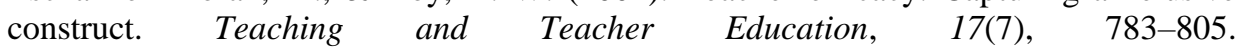
https://doi.org/10.1016/S0742-051X(01)00036-1

Tschannen-Moran, M., \& Woolfolk, H. A. (2007). The differential antecedents of self- 
efficacy beliefs of novice and experienced teachers. Teaching and Teacher Education, 23(6), 944-956.

Tulbure, C. (2011). Differentiated instruction for pre-service teachers: An experimental investigation. Procedia - Social and Behavioral Sciences, 30, 448-452.

Usher, L. R. (2013). Teachers perception and implementation of differentiated instruction in the private elementary and middle schools. (Doctoral Dissertation). Available at ProQuest Thesis and Dissertations. (UMI: 3565597).

VanTassel-Baska, J., \& Stambaugh, T. (2005). Challenges and possibilities for serving gifted learners in the regular classroom. Theory Into Practice, 44(3), 211-217.

Weaver, B., \& Wuensch, K. L. (2013). SPSS and SAS programs for comparing Pearson correlations and OLS regression coefficients. Behavior Research Methods, 45(3), 880895. https://doi.org/10.3758/s13428-012-0289-7

Wu, S.-C. (Angel), \& Chang, Y.-L. (Aldy). (2015). Advancing kindergarten teachers' knowledge and capabilities of differentiated instruction associated with implementation of thematic integrated curriculum. Procedia - Social and Behavioral Sciences, 177, $246-250$.

$\mathrm{Xu}$, S. (2012). Strategies for differentiated instruction for English learners. Using Informative Assessments Towards Effective Literacy Instruction, 1, 349-378. 